\title{
Common issues in the medication use processes in nursing homes: a review of medication use quality improvement strategies
}

\author{
Peter J. Hughes ,' Maisha Kelly Freeman, Rachel M. Slaton \\ Samford University McWhorter School of Pharmacy, Birmingham, AL USA
}

Received: November 9, 2015

DOI: $10.5430 /$ jnep.v6n7p81
Accepted: January 29, $2016 \quad$ Online Published: March 4, 2016

URL: http://dx.doi.org/10.5430/jnep.v6n7p81

\begin{abstract}
Background: A continuous evaluation of safety practices in nursing homes and long-term care (LTC) facilities is needed. Numerous studies have highlighted the deficiencies in safety processes of nursing homes compared with institutional practice despite the fact that many residents in the nursing home setting also suffer from complex medical conditions and are receiving multiple medications to treat the comorbidities. As part of larger grant initiative, an extensive search was conducted to identify common problems in nursing facilities and potential strategies for improvement. This review highlights common problems in the medication use process in nursing facilities and strategies to improve processes and general resident safety based upon pertinent findings from the literature.

Findings: There are proven medication safety strategies utilized in institutions that should be a foundational practice in nursing and LTC facilities. These strategies include, but are not limited to, reduction of polypharmacy and increased sensitivity to and prioritization of medication therapy monitoring processes, which will assist in the creation of a culture of safety. Specific goals of this process includes frequent education and encouraged use of best practices surrounding handling of high-alert medications, proper drug administration (e.g., crushing medications), drug interactions and reporting of adverse medication events.

Conclusion: Medication use process failures are common in nursing and LTC facilities. However, an integrated approach can be used to mitigate some of the common problems. Pharmacists and nurses should work more closely to implement proven medication safety strategies. Implementing these strategies in concert with improved communication between team members can benefit residents by preventing avoidable events and hospitalizations.
\end{abstract}

Key Words: Medication use process, Nursing home, Long-term care, Hospitalization

\section{INTRODUCTION}

In general, an adverse drug event (ADE) is "any undesirable experience associated with the use of a medical product in a resident."[1] By definition, ADEs include those that are nonpreventable (adverse drug reactions, ADRs) and those that are preventable (medication errors). An ADR is a "response to a drug which is noxious and unintended and which occurs at doses normally used in man for prophylaxis, diagnosis, or therapy of disease or for the modification of physiologic function." ${ }^{2]}$ A medication error is generally defined as any preventable event occurring in the medication use process (e.g., prescribing, transcribing, dispensing, administration,

\footnotetext{
* Correspondence: Peter J. Hughes, PharmD; Email: pjhughes@samford.edu; Address: Samford University McWhorter School of Pharmacy, Birmingham, AL, USA.
} 
monitoring) that causes (or has the potential to cause) resident harm or inappropriate medication use. ${ }^{[3-5]}$ Actual errors are those that reach the resident, prevented errors (or "near misses") are errors that are identified prior to reaching the resident and potential errors are those situations that pose a hazard and may develop into errors. ${ }^{[1,6]}$

Approximately $19 \%-42 \%$ of all medication doses administered in nursing facilities are associated with medication errors. ${ }^{[7]}$ In addition, new data among Medicare beneficiaries suggests that $22 \%$ of skilled nursing home residents experienced an adverse event (AE) within first 35 days of their stay; of these, $37 \%$ were due to medications. ${ }^{[8]}$ By definition, these AEs may have resulted in prolonged stay in a nursing home or hospitalization, permanent harm or death. Analysis of the AEs found that $69 \%$ were preventable. ${ }^{[8]}$ In general, evidence indicates that preventable ADEs caused by errors occur at a rate of 1 per 100 resident-months. ${ }^{[7]}$ In addition, ADEs in a nursing home are costly. It is estimated that for every $\$ 1$ spent on medications, $\$ 1.33$ is spent on the treatment of harm caused by the medications. ${ }^{[1]}$ The costs of hospitalization associated with ADEs has been estimated to be $\$ 8,372$ per event. ${ }^{[8]}$ Medication errors in nursing facilities are due to a variety of reasons including polypharmacy, lack of physician oversight, and high turnover rates of nursing staff. Adverse drug reactions may go unrecognized due to the limited training of front-line staff in basic pharmacology and AEs of commonly used medications.

Few studies have been conducted to evaluate medication errors in nursing facilities. However, data from a crosssectional analysis between the North Carolina medication errors database (Medication Error Quality Initiative [MEQI]) during 2010-2011 and the National Nursing Home Survey (NNHS) from 2004 identified the frequency of errors among drug classes as well as characteristics of errors (i.e., the types of errors, phase in the medication use process, frequency of errors, and whether the error occurred within 7 days of a resident transitioning) from 398 nursing facilities in the state. In this study, errors were most common in the following pharmacological classes: analgesic (12.27\%); anxiolytics, sedatives, and hypnotics $(8.39 \%)$; antidiabetic agents $(5.86 \%)$; anticoagulants $(5.04 \%)$; anticonvulsants (4.05\%); antidepressants (4.05\%); laxatives (3.13\%); ophthalmic preparations $(2.77 \%)$; antipsychotics $(2.47 \%)$; and diuretics $(2.34 \%)$. Among the types of errors (wrong resident, wrong dose, wrong drug, wrong administration, wrong follow-up, other) evaluated, the most frequent type of error in each class was "wrong dose". Collectively, the largest proportion of errors occurred in the administration (31.2\%-72.2\%) and documentation $(22.4 \%-61.6 \%)$ phases of the medication use process for these medication classes. Although documen- tation was not defined, pharmacy documentation refers to "nurse documentation completed after dose given; whether or not the nurse documentation is accurate; and if the physician/pharmacist is notified of any adverse reaction". Harm to residents occurs most frequently with diuretics $(2.8 \%)$ and anticoagulants (1.8\%). Repetitive errors occurred most frequently with diuretics (45.1\%) and ophthalmic preparations $(38.9 \%) .{ }^{[9]}$ Errors occurring during resident care transitions are most problematic with diuretics (16.6\%) and anticoagulants (15.7\%). ${ }^{[7]}$ These data provide a starting point for nursing facilities seeking to develop medication safety initiatives and improve the quality of care provided to their residents.

The purpose of this review is to discuss some of the most common issues associated with the medication use process (e.g., polypharmacy; lack of ADE reporting; look alike, sound alike drugs; error-prone abbreviations; high-alert medications; "do not crush" medications) and proven medication safety strategies to achieve appropriate clinical outcomes in nursing home residents.

\section{Polypharmacy}

Polypharmacy is an independent risk factor for hospitalization in nursing home residents. Polypharmacy has several different definitions in the literature including "the presence of six or more concurrent medications", "use of at least one potentially inappropriate drug", and the "concurrent use of $\geq 9$ medications". ${ }^{[10]}$ Medication errors increase as a result of an increasing number of medications consumed by nursing home residents. Therefore, reducing inappropriate medication use (i.e., duplicative therapy, unnecessary medications) for nursing home residents is important in reducing medication errors and subsequent hospitalizations due to polypharmacy.

Data on the frequency of polypharmacy in nursing facilities and the subsequent outcomes (e.g., cardiac, endocrine, pulmonary diseases, memory problems, depression, and anxious behaviors) for residents is variable. Bronskill et al. evaluated the rates of polypharmacy across LTC facilities in Ontario, Canada. A total of 64,394 residents aged 66 years and older residing in 589 nursing facilities in the fall of 2005 were assessed. In this study, the majority of residents $(n=10,007)$ were taking 9 or more medications. Residents more likely to be receiving 9 or more medications had multiple comorbidities. In addition, patients who received $\geq 9$ medications experienced more circulatory diseases ( $82 \%$ vs. $61.6 \%$, digestive disorders $(21.1 \%$ vs. $17.9 \%)$, endocrine and metabolic disorders (55\% vs. $33 \%)$, pulmonary diseases $(23.1 \%$ vs. $13.5 \%)$ and infectious diseases $(1.6 \%$ vs. $1.4 \%) .{ }^{[11]}$ Similarly, Dwyer et al. evaluated polypharmacy in nursing home 
residents in the United States, based on the results of a 2004 NNHS. In this study, polypharmacy was defined as the use of 9 or more concurrent medications. A total of 13,403 residents participated in the survey. The prevalence of polypharmacy was determined to be $40 \%$ in 2004 . Residents who had the highest odds of receiving polypharmacy were female, white, had Medicaid as a primary payer, had $>3$ comorbidities, needed assistance with $\geq 4$ activities of daily living, had a length of stay since admission of 3 to $<6$ months, and received care in a small, not-for-profit nursing home. The classes of drug products that were most frequently associated with polypharmacy included gastrointestinal agents (laxatives, 47.5\%; agents for acid/peptic disorders, 43.3\%), drugs that affect the central nervous system (antidepressants, $46.3 \%$; antipsychotics or antimanics, $25.9 \%$ ), and pain relievers (nonnarcotic analgesics, $43.6 \%$; antipyretics, $41.2 \%$; antiarthritics, $31.2 \%) .{ }^{[3]}$

Tamura et al. evaluated outcomes associated with polypharmacy in nursing home residents. ${ }^{[12]}$ In this systematic review, 9 articles were included that assessed hospitalizations associated with polypharmacy in the nursing home setting. The majority of the studies (14 out of 15 studies) revealed that increasing number of medications was associated with a higher degree of hospitalization. Dedhiya et al. found a direct relationship between the number of medications received and the odds of hospitalization. Compared to a control group receiving 1-10 medications per year, patients receiving $>10$ medications on average experienced increasing risk based upon number of medications received; 11-15 medications (1.28 [95\% CI, 1.04-1.57; $P=.018]$; 16-20 medications, OR, 1.46 (95\% CI, 1.19-1.81; $P<.001)$; $>20$ medications, OR, 1.63 (95\% CI, 1.32-2.02; $P<.001)$. Seven out of the nine studies assessed indicated a greater likelihood for ADRs ( $\mathrm{n}=8$ studies were assessed for ADRs, drug-related problems was reported in one study) or drug-drug interactions ( $\mathrm{n}=$ 2) with a larger number of medication use. Polypharmacy was also associated with an increased incidence of mortality. ${ }^{[13]}$ In one study, residents receiving $\geq 12$ medications were more likely to be hospitalized than those who were receiving $<12$ medications. ${ }^{[14]}$ In another study, residents using more than 6 medications per week was associated with hospitalizations. ${ }^{[4]}$ Other studies have revealed that residents taking more than 5 and 7 medications were associated with increased hospitalizations. ${ }^{[5,15-18]}$

Measures to reduce polypharmacy should be implemented to reduce subsequent hospitalizations. Some initiatives that can be targeted include: omitting PRN orders that have been on the MAR for $>30$ days; evaluating for therapeutic duplication and discontinuing/tapering medications, if needed; matching all disease states and drug therapy to determine if there are any gaps between the two; and/or discontinuing/tapering medications associated with adverse drug effects in the elderly population (e.g., Beer's Criteria, STOPP/START criteria, etc.). The Beer's Criteria ${ }^{[19]}$ and STOPP/START ${ }^{[20]}$ tools can be used to assist in determining inappropriate medications in this population. Some facilities have also developed medication safety teams. Medication safety teams are comprised of health care professionals from diverse disciplines who meet to reduce the risk of medication errors and ADRs in LTC residents. Teams have also been an efficient way to reduce polypharmacy. These teams meet on a predefined basis to discuss each resident's MAR and provide recommendations to the physicians regarding which medications may be good candidates for discontinuation.

\section{REPORTING OF ADES}

In 1999, the Institute of Medicine (IOM) released a report titled "To Err Is Human: Building a Safer Health System" that revealed the magnitude of harm caused by medical errors in healthcare by listing "medical errors" in the top 10 causes of death in the United States. ${ }^{[21]}$ The report summarized identified flaws in the healthcare system and methods to improve them. Table 1 outlines proven medication safety strategies highlighted in the report for averting or mitigating errors with medications. ${ }^{[21]}$ While some are specific to hospital practice, most of the recommendations can be easily extrapolated to the LTC setting. For example, all nursing facilities should be documenting and analyzing medication errors based on a system-oriented approach instead of a person-based approach. In addition, standardizing policies and processes (i.e., prescribing rules, patient care protocols, acceptable abbreviations, medication administration times, dosing scales, and medical equipment) within an institution can aid in identifying inconsistencies that may lead to errors if employees are adequately trained. Implementation of physician order entry in nursing facilities could also avert transcription/documentation errors since numerous healthcare providers are generally involved in order transcription and order entry into computer systems in LTC. Patient care systems that have pharmaceutical decision support can minimize errors as well access to medication information at the point of care. Lastly, keeping high-alert and hazardous medications under lock and key and accessible only by qualified healthcare providers can reduce the likelihood of severe medication errors. ${ }^{[21]}$ In addition, use of other basic safeguards can help identify errors and prevent the resident from being harmed. Safeguards include review of basic information each time a medication is prescribed, ordered/transcribed, dispensed, administered or monitored. Figure 1 outlines basic safeguards within each phase of the medication use process. 


\section{Checks within the}

\section{Medication Use Process (MUP)}

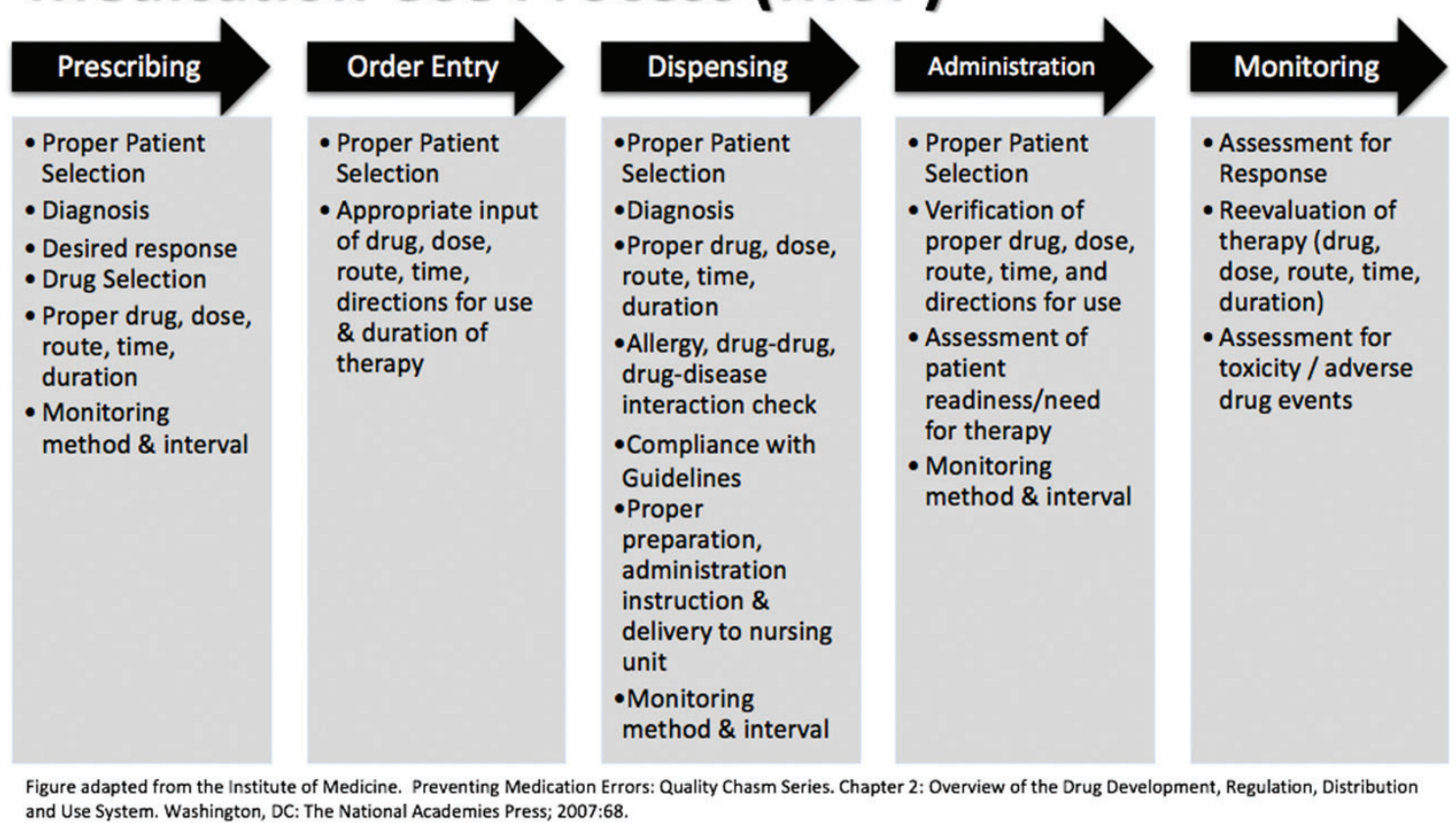

Figure 1. Basic Safeguards in the Medication Use Process ${ }^{[42]}$

Table 1. Medication safety strategies to avert or mitigate medication errors. ${ }^{[21]}$

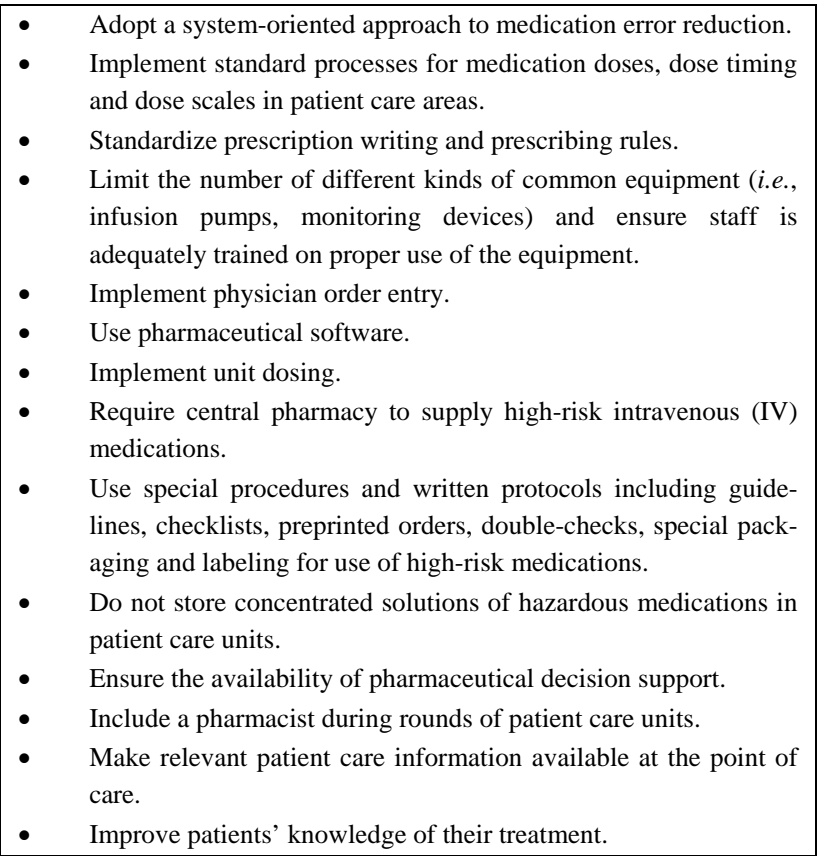

Since the release of the IOM report and with the support of the Joint Commission (TJC) and the Institute for Safe Medication Practices (ISMP), institutions have strived to evaluate quality assurance on a continuous basis. With more stringent oversight by individual states as well as attention from the media, providers in LTC and skilled nursing facilities may soon be expected to demonstrate quality assurance and performance improvement initiatives to maintain accreditation and funding. ${ }^{[22]}$

In general, reporting of ADEs is a foundational quality improvement initiative. Institutions that collect, analyze, benchmark and trend error data on a continuous basis can use this information to identify and improve upon system processes as well as human deficits to prevent future medication errors. This data establishes an internal point of reference on the quantity, location and types of medication errors in a nursing home and can be used to direct quality improvement initiatives. In nursing facilities, most medication error or ADR information is communicated informally through change-ofshift reports instead of formal reporting. ${ }^{[23]}$ While most staff feel comfortable reporting ADR information, it is known that $>85 \%$ of staff believe disciplinary action is taken against a person reporting an error. Informal reporting lends to narrow perspectives on the sources of errors and inabilities to fix ineffective processes. ${ }^{[23]}$

Nursing home leadership can engage employees by providing a clear, simple and structured ADE reporting process. Reporting of ADEs must be encouraged and actions by administrators must be evident to help employees understand its 
value. Nursing facilities with successful ADE reporting processes have many advantages over other facilities. Reporting of ADE information helps leaders identify unexpected events and provides for timely investigation of events. In general, the data collected helps the nursing home to identify risk and potentially dangerous situations (potential errors). ${ }^{[24]}$ Staff who observe improved resident safety outcomes from the cycle of "reporting, action, and improvement" will be engaged and empowered that they are helping to improve the safety of the nursing home. For facilities with a history of penalizing employees who report events, implementation of a reward-based system in lieu of a punishment-based system is one method that can motivate reporting.

With high employee turn-over rates, it is essential that ADE training occur during orientation and that regular reviews of the process and positive outcomes take place at staff meetings. Nursing facilities seeking to improve ADE reporting systems should consider utilizing medication safety teams to lead the effort. A representative from the medication safety team generally attends staff meetings to report ADEs that occurred, system improvements that are to be implemented to avert future events and answer questions and concerns of employees. Once employees witness change in a nursing home based on submitted reports, they can be encouraged, become vested in the system and continue to report.

\section{LOOK-ALIKE, SOUND-ALIKE DRUGS AND ERROR-PRONE ABBREVIATIONS}

Drug names that look- or sound-alike (LASA) increases the risk for medication errors. ${ }^{[25]}$ Many institutions have coined these medications "SALAD" (sound-alike, look-alike drugs) to aid in discussion of agents with these characteristics. In addition, when LASA/SALAD medications also have similar packaging, overlapping dosage ranges and similar suffixes (e.g., ER, CR, XR), the potential for error is even greater. Since there is no standardized meaning for the frequency of administration for the suffixes, errors commonly occur that can lead to subtherapeutic drug levels or toxicity in patients. For example, if a prescription is written for immediate release morphine sulfate (morphine sulfate IR) by mouth every 4 hours as needed and morphine sulfate controlled release (morphine sulfate $\mathrm{CR}$ ) is erroneously selected and dispensed in its place, a patient would easily overdose and potentially die. Thus, close attention must be paid to suffixes each time an order is written or transcribed. ISMP maintains and continuously updates lists of LASA/SALAD name pairs that have been commonly confused when handwritten or communicated verbally. The Confused Drug Name List is a collective register of errors reported to the ISMP Medication Error Reporting Program (ISMP MERP). ${ }^{[25]}$ In addition, tall-man letters are used to distinguish similarly spelled drug names from one another as a preventive measure to avoid medication errors.

Tall-man letters (mixed case lettering) highlight dissimilarities in drug names that have similar spelling (e.g., ALPRAZolam, LORazepam) or may sound alike when verbalized (e.g., QUEtiapine, OLANzapine) by capitalizing portions of the elements of the drug name. ${ }^{[26]}$ The specific letters of commonly confused drug names has been standardized by ISMP. In the event a drug is identified as problematic and is not included on the FDA and ISMP Lists of Look-Alike Drug Names with Recommended Tall Man Letters, the methodology (CD3) used by ISMP should be used to develop the tall-man lettering for the products. Addition of tall-man lettering to all electronic and printed displays of drug names in a nursing home can be beneficial for reducing errors by improving the accuracy of drug selection. Medication names must be standardized on medication packaging/labeling, within resident health information systems, MARs, automated medication management systems (Pyxis ${ }^{\mathrm{TM}}$, Omnicell ${ }^{\mathrm{TM}}$ etc.), and on handouts and signage used by healthcare professionals. In addition, the use of tall-man lettering alerts healthcare personnel that the specific product has been commonly associated with error and extra caution is needed. ${ }^{[27]}$ At this time, it is not suggested that tall-man lettering be used on materials provided to residents. ${ }^{[26]}$ Use of tall-man lettering is supported by safety organizations including ISMP, FDA, and TJC.

Although use of abbreviations or acronyms is believed to save time, use of these actually wastes time and increases the potential for medication errors. ${ }^{[28]}$ Specifically, in a nursing home setting with employees of varying clinical education and experience, use of abbreviations may complicate workflow and cause communication errors. Institutions should maintain a list of unacceptable abbreviations and ensure staff is knowledgeable of the list and know to question the true meaning of abbreviations when identified as unclear. Both ISMP and TJC maintain lists of unacceptable abbreviations that have been identified based on case reports. Abbreviation of drug names can lead to tragic mix-ups. For example, "MSO4" could be interpreted as morphine sulfate or magnesium sulfate. Both of these drugs are high alert medications that can cause significant harm. Abbreviation errors of routes of administration are also common. Harmful reports of medications being administered sublingually ("SL") verses subcutaneously ("SC or SQ") led to the addition of these abbreviations to the list and the subsequent recommendation to use "SubQ" only. Lastly, abbreviation of medication dosages can lead to significant under or overdoses of medication since the abbreviation may be read as another number following 
the dose. For example, the word "units" should be used in place of " $U$ " in insulin orders to prevent the " $U$ " from being read as a zero (e.g., $6 \mathrm{U}$ of insulin $v s .6$ units). ${ }^{[28]}$ Table 2 contains internet hyperlinks to websites that contain helpful medication safety information.

Table 2. Helpful medication safety websites

\begin{tabular}{|c|c|}
\hline $\begin{array}{l}\text { Confused Drug } \\
\text { Names }\end{array}$ & $\begin{array}{l}\text { http://www.ismp.org/Tools/confuseddrugname } \\
\text { s.pdf }\end{array}$ \\
\hline Tall Man Letters & http://www.ismp.org/Tools/tallmanletters.pdf \\
\hline $\begin{array}{l}\text { Error Prone } \\
\text { Abbreviations }\end{array}$ & $\begin{array}{l}\text { http://www.ismp.org/Tools/errorproneabbrevia } \\
\text { tions.pdf }\end{array}$ \\
\hline $\begin{array}{l}\text { High Alert } \\
\text { Medications }\end{array}$ & $\begin{array}{l}\text { http://www.ismp.org/Tools/highAlertMedicati } \\
\text { onLists.asp }\end{array}$ \\
\hline $\begin{array}{l}\text { Do Not Crush } \\
\text { Medications }\end{array}$ & http://www.ismp.org/Tools/DoNotCrush.pdf \\
\hline $\begin{array}{l}\text { Top } 10 \text { dangerous } \\
\text { drug interactions }\end{array}$ & $\begin{array}{l}\text { http://www.amda.com/tools/clinical/m3/topten. } \\
\text { cfm }\end{array}$ \\
\hline $\begin{array}{l}\text { FDA: Avoid Drug } \\
\text { Food Interactions }\end{array}$ & $\begin{array}{l}\text { http://www.fda.gov/downloads/Drugs/Resourc } \\
\text { esForYou/Consumers/BuyingUsingMedicineS } \\
\text { afely/EnsuringSafeUseofMedicine/GeneralUse } \\
\text { ofMedicine/UCM229033.pdf }\end{array}$ \\
\hline $\begin{array}{l}\text { Improving Resident } \\
\text { Safety in Long-Term } \\
\text { Care Facilities }\end{array}$ & $\begin{array}{l}\text { http://www.ahrq.gov/professionals/systems/lon } \\
\text { g-term-care/resources/facilities/ptsafety/index. } \\
\text { html }\end{array}$ \\
\hline $\begin{array}{l}\text { Medication Error } \\
\text { Reporting Program }\end{array}$ & $\begin{array}{l}\text { https://www.ismp.org/errorReporting/reportErr } \\
\text { ortoISMP.aspx }\end{array}$ \\
\hline MedWatch & $\begin{array}{l}\text { http://www.fda.gov/Safety/MedWatch/default. } \\
\text { htm }\end{array}$ \\
\hline
\end{tabular}

\section{High-ALERT MEDiCATIONS}

Medications that may cause significant harm when used in error are referred to as "high-alert medications". While these medications may not be the most frequent cause of errors, when errors occur with medications listed as high-alert, the potential for harm is increased and the outcomes for the resident may be devastating. The mnemonic "A PINCH" has been used to aid in remembering medications with a narrow therapeutic index since only "a pinch" of these medications can result in severe harm. The letters stand for Anti-infectives, Potassium (and other electrolytes), Insulin, Narcotics (and other sedatives), Chemotherapy, and Heparin (and other anticoagulants). ${ }^{[29]}$

High-alert medications require special attention and safeguards need to be in place to protect the resident. An example of a safeguard is monitoring processes that evaluate the dose and frequency of anti-infective agents in elderly patients who may have renal and/or hepatic insufficiency. Also, assuring the duration of anti-infectives is appropriate based on the severity of the condition being treated. Healthcare professionals should be educated on the different types of insulin available and be able to recognize the sign and symptoms of low blood sugar. Nurses should read the label on the insulin vial or pen each time and not rely on visual recognition of the product since most of the pens by the same manufacturer look similarly. Thus, nursing facilities should identify policies and procedures on the storage of insulin pens to limit wrong drug errors. Use of insulin pens can be helpful in providing accurate doses of insulin; however, the dose of insulin should be compared to the order to ensure the appropriate amount is administered. One strategy regarding rapid-acting insulins is to administer them at meals in lieu of "meal time" since patients may receive the insulin and then fail to eat quickly enough before it takes action.

While nursing homes may already have a policy and procedure in place for handling narcotics, it is important that it is updated and includes information on newer dosage forms. There are numerous dosage forms (e.g., controlled release, transdermal, injectable) available for narcotics that nurses should be able to distinguish. In addition, education on the signs and symptoms of narcotic overdose and familiarity with medications used in emergency treatment is crucial. Although most will think of chemotherapy agents as hospital drugs, there are chemotherapeutic agents used in nursing facilities. For example, methotrexate once weekly is commonly used in patients with rheumatic conditions. An important medication safety initiative regarding methotrexate is alerting nurses that methotrexate should never be given on a daily basis in LTC. Lastly, policies and procedures should be put in place for the monitoring of heparin and oral anticoagulants (i.e., warfarin). Nurses can also help identify patients who may be at risk for blood clots (e.g., obesity, immobility, infection, injury or surgery) and alert healthcare professionals so proper treatments can be put in place. Further, the medication safety strategies outlined in the IOM report recommend safeguards including limiting distribution of high risk medication to a centralized location and development and implementation of special procedures (i.e., double-checks, special packaging and labeling) and written protocols (i.e., guidelines, checklists, preprinted orders) for these medications that must be followed with each issuance. $^{[21]}$

\section{6. "Do Not CRUSh" MEdicATIONS}

With residents in the nursing home taking so many medications, it can be troublesome when a resident has difficulty swallowing and the dosage form of the medication needs to be altered for optimal administration. Medications in the nursing home are often crushed to ease administration; however, errors can occur if medications with special release mechanisms (extended-release, [ER or XR], controlledrelease [CR], sustained release [SR]) are crushed. Because these medications contain large doses of drug and are designed to slowly release the drug over a longer period of 
time, crushing the medication can result in large amounts of medication being rapidly released and resultant drug toxicity. For residents receiving enteral nutrition, additional caution is warranted when crushing medications as some medications may be physically or chemically incompatible with common enteral nutrition formulas. Medication package inserts and nutrition product information should be consulted to determine appropriateness of crushing and mixing medications with enteral nutrition products. ${ }^{[30]}$ A list of medication that should not be crushed may be obtained through an Internet link provided in Table 1. ${ }^{[31]}$

\section{DRUG-DRUG AND DRUG-FOOD INTERAC- TIONS}

Drug-drug interactions are physical or chemical interactions between a medicine and another medicine, herbal supplement, food, drink or other environmental agent. ${ }^{[31]}$ These interactions vary greatly in terms of severity and duration. Additionally, some interactions may present with acute exposure to two interacting medications, whereas other interactions only manifest when chronic exposure occurs. Furthermore, the likelihood of drug-drug interaction increases with the number of medications a resident receives. Original estimates on the rate of drug-drug interactions was $7 \%$ in persons receiving 6-10 medications and $40 \%$ in those receiving 16-20 medications. ${ }^{[32]}$ However, more recent data offers conflicting estimates as the rates of significant drug-drug interactions varies by resident type (i.e., age, underlying comorbidities) and healthcare setting (e.g., primary care clinic, hospital, nursing home).

One of the essential roles of pharmacy practice is the prospective screening for significant drug-drug interactions within a resident's drug regimen by a licensed pharmacist. However, there may be facility-specific factors that lead to drugdrug interactions outside the scope of a pharmacist's review. These can include: use of floor-stock (i.e., acetaminophen, ibuprofen, multivitamins) that is not coordinated or reviewed by a pharmacist, use of medicines brought into the nursing home by a family member, or use of herbal supplements or nutritional supplements not registered in the pharmacy medication list. It is extremely important for nursing home clinical staff and the visiting consultant pharmacist to be knowledgeable of any prescription, over-the-counter or nutritional supplements a resident receives in addition to the medications listed on the MAR. Furthermore, these situations should be minimized. Many software packages offer drug interaction screening tools. Use of more than one of these tools is recommended to augment clinical judgment in addition to regular consultation of consultant pharmacy staff by facility nurses.
A more specific type of drug-drug interaction, a drug-food interaction is an "alteration of the pharmacokinetics (i.e., what the body does to the drug) or pharmacodynamics (i.e., what the drug does to the body) of a drug or nutritional element or a compromise in nutritional status as a result of the addition of a drug". [32] It is well documented that certain food products or food additives interact with certain medications, and the elderly are at an increased risk for these interactions because they consume a disproportionate amount of the medications dispensed in the United States. ${ }^{[32,33]}$ Also, the elderly are at increased risk for these interactions due to agerelated decline in organ function, as performance of essential organs for processing medicines such as the kidney and liver decline over time. ${ }^{[33]}$ The nature of a drug-food interaction is variable; the presence of food (including enteral feeding solutions) in the stomach can alter drug absorption and sometimes these interactions are actually desirable interactions (e.g., administration of hydrocodone/acetaminophen with food to decrease nausea). Additionally, certain foods can alter how a drug is metabolized or "processed" by the body by interfering with drug target receptor sites or by slowing or accelerating the clearance of the drug from the body. ${ }^{[34]}$ Certain food and beverage products have been linked to significant drug-food interactions (e.g., grapefruit juice, brussels sprouts, cabbage, licorice, broccoli, alcohol) and regular or acute, moderate-to-heavy intake of these foods or beverages by a resident is not a trivial matter. Due to the benign nature of many drug-food interactions the severity of these issues is often overlooked, however, certain drug-food interactions can lead to serious (and sometimes fatal) AEs.

Table 2 provides lists from the FDA, of common examples and strategies of how to avoid drug-food interactions. ${ }^{[35]}$ These listings are not considered to be exhaustive. It is important to become familiar with the proper administration of medicines in relation to meal times in order to maximize effectiveness and resident well-being, while minimizing the risk for a medication error, as improper administration of medications in relation to meals is considered a medication error.

\section{MEDICATION THERAPY MONITORING AND QUALITY IMPROVEMENT}

Governmental regulations (i.e., OBRA-87), advocate for high quality of life for nursing home residents, which includes avoidance of unnecessary medications, a major contributing factory of morbidity and mortality in the nursing home population. ${ }^{[19,36]}$ More objectively, the goal of regulations, specifically F-329 (unnecessary drugs), is to monitor the medication use process, including the monitoring for effect (or lack thereof) as well as for adverse effects and drug- 
induced disease states (e.g., dehydration from diuretic therapy, diabetes from certain antipsychotic agents). In a 12month cohort study by Gerwitz et al., over $50 \%$ of ADEs in 18 community-based nursing facilities were deemed as preventable, with $70 \%$ of these preventable events being associated with monitoring errors. ${ }^{[37]}$ follow up study by the same group in 2005 determined that the proportion of preventable ADEs occurring in the monitoring stage increased to $80 \%{ }^{[38]}$ Specifically, F-329 states, "Each resident's drug regimen must be free from unnecessary drugs. An unnecessary drug is any drug when used: in excessive dose (or duplicate therapy); or for excessive duration; or without adequate monitoring; or without adequate indication for use or; in the presence of adverse consequences which indicate the dose should be reduced or discontinued or; any combination of the reasons above." ${ }^{[39]}$ Thus, the process of monitoring medication effectiveness and for identifying side effects/drug interactions of drug therapy is clearly included in federal survey regulations. The process of monitoring can include complex clinical monitoring of certain high-risk medications (e.g., warfarin, insulin) as well as periodic assessment for neurologic or functional changes in resident status.

These changes in status (termed geriatric syndromes) are oftentimes indicators of adverse consequences associated with drug therapy and include: weight changes, GI bleeding, behavioral changes, physical discomfort or pain, non-GI bleeding or bruising, changes in mental status, bowel dysfunction, rash or pruritus, dehydration, respiratory difficulties, urinary retention or incontinence, excessive sedation or insomnia, dysphagia, seizure activity, falls or dizziness, depression. ${ }^{[36]}$ Medications should be considered as a causative factor for any of these syndromes in older adults who present with new or worsening symptoms as an effort to avoid a "prescribing cascade" situation, a known contributor to geriatric polypharmacy. ${ }^{[36]}$

When monitoring for ADEs, proactive and anticipatory approaches, such as assessment tools (e.g., Abnormal Involuntary Movement Scale, Geriatric Depression Scale, MiniMental State Exam, Functional Assessment Staging, etc.) are best. ${ }^{[40]}$ However, reactive approaches to resolving medication-related problems may be necessary to implement system-wide improvement and to identify areas of improvement with monitoring of pharmacotherapy in a nursing home's medication use process. Identifying trigger drugs or antidotes that have been used to treat drug-related problems can be a useful tool.

Handler et al. developed a consensus list of minimum data set signals that can be used to detect potential ADEs in the nursing home. ${ }^{[41]}$ The authors recruited a multidisciplinary expert panel to reach consensus on certain triggers for potential ADEs. Out of a list of 80 potential signals, the experts reached consensus on 40 ADE signals. The highest consensus scores were reached for naloxone (opioid analgesics), phytonadione (vitamin K), dextrose, glucagon or glucose (hypoglycemic agents), clinical hypoglycemia (hypoglycemic agents), supratherapeutic INR (warfarin) and triggering the falls resident assessment protocol (certain anticholinergic medications). Additionally, certain drugs require regular or frequent clinical monitoring (i.e., narrow-therapeutic index drugs) and can include warfarin, digoxin, phenytoin, lithium and theophylline. The expert panel in the Handler study also suggested that quinidine, procainamide, disopyramide be frequently monitored as well, as excessively high or low serum levels of these medications also serve as a trigger for a potential adverse effect. ${ }^{[41]}$

When developing or revising medication monitoring policies it is important to keep the following key principles in mind. ${ }^{[40]}$ First, medication monitoring is a multidisciplinary process that requires the skills and talents of the healthcare team and also involves subjective and objective assessments. Special focus and attention should be paid to the expertise and recommendations of the consultant pharmacist. Second, monitoring for neuropsychiatric symptoms (e.g., tiredness, hallucinations, confusion, delirium) should be the focus of medication monitoring programs, as strong evidence indicates that these symptoms precipitate the most common ADEs in the nursing home population. ${ }^{[37]}$ Third, any new symptom should trigger consideration and review of current medication therapy in a given resident. Fourth, specific types of medications have been deemed most problematic. These medications include atypical antipsychotics, anticoagulants, angiotensin converting enzyme (ACE) inhibitors, loop diuretics and intermediate acting benzodiazepines; there should be structured monitoring processes in place for these medicines to prevent and identify drug-related problems in residents who receive them. Lastly, polypharmacy is a key driver of drug related problems, specifically drug-drug interactions that lead to an unintended drug-induced disease state. Every effort should be made to minimize unnecessary medications. ${ }^{[37]}$

\section{Conclusions}

Medication use process issues are common in nursing facilities. However, an integrated approach should be used to mitigate some of the most common problems which have been reviewed in this work. Pharmacists and nurses should work together with other health care professionals to implement these proven medication safety strategies. Forming integrated medication safety teams in individual nursing 
homes is an excellent start. These multidisciplinary teams can include any stakeholder group, but the director of nursing and the consultant pharmacist should central to the model to improve likelihood of success. Tackling one problem at a time coupled with realistic goals is the best approach to have sustained effect and to ensure motivation for change. Together, nurses, pharmacists and other professionals can work together to reduce the likelihood of avoidable hospitalizations and other negative health events in nursing home residents.

\section{REFERENCES}

[1] Nebeker JR, Barach P, Samore MH. Clarifying Adverse Drug Events: A Clinician's Guide to Terminology, Documentation, and Reporting. Ann Intern Med. 2004; 140: 795-801. http://dx.doi.org/10. 7326/0003-4819-140-10-200405180-00017

[2] American Society of Health-systems Pharmacists (ASHP) guidelines on adverse drug reaction monitoring and reporting. Available from: https://www.ashp.org/doclibrary/bestpractices/ medmisgdladr . aspx. Accessed January 23, 2016.

[3] Dwyer LL, Han B, Woodwell DA, et al. Polypharmacy in nursing home residents in the United States: results of the 2004 National Nursing Home Survey. Am J Geriatr Pharmacother. 2010 Feb; 8(1): 63-72.

[4] Intrator O, Castle NG, Mor V. Facility characteristics associated with hospitalization of nursing home residents: results of a national study. Med Care. 1999; 37: 228-237. http://dx.doi.org/10.1097/0 0005650-199903000-00003

[5] Ruggiero C, Dell'Aquila G, Gasperini B, et al. Potentially inappropriate drug prescriptions and risk of hospitalization among older, Italian, nursing home residents: the ULISSE project. Drugs Aging. 2010; 27 : 747-758. PMid:20809664. http://dx.doi .org/10.2165/11538 240-000000000-00000

[6] American Society of Health-systems Pharmacists (ASHP). Guidelines on Preventing Medication Errors in Hospitals. Available from: http://www.ashp.org/DocLibrary/BestPractices/ MedMisGdlHosp. aspx. Accessed January 23, 2016.

[7] Desai RJ, Williams CE, Greene SB, et al. Exploratory evaluation of medication classes most commonly involved in nursing home errors. JAMDA. 2013; 14: 403-408.

[8] Department of Health and Human Services Office of Inspector General. Adverse Events in Skilled Nursing Facilities: National Incidence Among Medicare Beneficiaries. February 2014 (OEI-06-1100370). Available from: http://oig.hhs.gov/oei/reports/ oei-06-11-00370.pdf. Accessed November 3, 2015.

[9] Guidelines on preventing medication errors in pharmacies and longterm care facilities through reporting and evaluation. Available from: https://www. ascp.com/resources/policy/upload/G ui97-Med\%20Errors.pdf. Accessed January 19, 2016.

[10] Zarowitz BJ. Polypharmacy: when is enough, enough? Geriatr Nurs. 2011 Nov-Dec; 32(6): 447-449.

[11] Bronskill SE, Gill SS, Paterson JM, et al. Exploring variation in rates of polypharmacy across long term care homes. J Am Med Dir Assoc. 2012 Mar; 13(3): 309.e15-21.

[12] Tamura BK, Bell CL, Inaba M, et al. Outcomes of polypharmacy in nursing home residents. Clin Geriatr Med. 2012 May; 28(2): 217236.

[13] Dedhiya SD, Hancock E, Craig BA, et al. Incident use and outcomes associated with potentially inappropriate medication use in older adults. Am J Geriatr Pharmacother. 2010; 8: 562-570. http://dx.doi.org/10.1016/S1543-5946(10)80005-4
[14] Grabowski DC, O'Malley AJ, Barhydt NR. The costs and potential savings associated with nursing home hospitalizations. Health Affairs. 2007; 26: 1753-1761. PMid:17978395. http://dx.doi.org/10. 1377/hlthaff.26.6.1753

[15] Cherubini A, Eusebi P, Dell'aquila G, et al. Predictors of Hospitalization in Italian Nursing Home Residents: The U.L.I.S.S.E. Project. J Am Med Dir Assoc. 2012 Jan; 13(1): 84.e5-10.

[16] Hui E, Wong E, Woo, J. Predictors of hospitalization and death in nursing home residents. Hong Kong Journal of Gerontology. 2000; 14: 63-65.

[17] Tang M, Woo J, Hui E, et al. Utilization of emergency room and hospitalization by Chinese nursing home residents: a cross-sectional study. J Am Med Dir Assoc. 2010; 11: 325-332. PMid:20511099. http://dx.doi.org/10.1016/j.jamda.2009.10.003

[18] Cooper JW. Adverse drug reaction-related hospitalizations of nursing facility residents: a 4-year study. South Med J. 1999; 92: 485-490. http://dx.doi.org/10.1097/00007611-199905000-00007

[19] American Geriatrics Society 2012 Beers Criteria Update Expert Panel. American Geriatrics Society updated Beers Criteria for potentially inappropriate medication use in older adults. J Am Geriatr Soc. 2012 Arp; 60(4): 616-31.

[20] O'Mahony, O'Sullivan D, Byrne S, et al. STOPP/START criteria for potentially inappropriate prescribing in older people: version 2. Age Ageing. 2014; 0: 1-6.

[21] Institute of Medicine. To err is human: building a safer health system. Washington, DC: national Academy Press. Available from: https://iom.nationalacademies.org/ /media/Files/Re port $\% 20$ Files/1999/To-Err-is-Human/To\%20Err $\% 20$ is $\% 2$ OHuman $\% 201999 \% 20 \% 20$ report $\% 2$ brief .pdf. Accessed January 23, 2016.

[22] Joint Commission launches nursing and rehabilitation center accreditation program. Joint Commission Perspectives. 2013; 33(2): 6-7.

[23] Handler SM, Nace DA, Studenski SA, et al. Medication error reporting in long-term care. Am J Geriatr Pharmacother. 2004; 2: 190-196. PMid:15561651. http://dx.doi.org/10.1016/j.amj opharm.2004.09.003

[24] Grissinger MC. Risk identification and data collection methods ISMP 2012 Medication Safety Intensive.

[25] Confused Drug Name List. Institute for Safe Medication Practices (ISMP). Available from: http://www.ismp.org/Tools/confu seddrugnames . pdf. Accessed January 23, 2016.

[26] FDA and ISMP Lists of Look-Alike Drug Names with Recommended Tall Man Letters. Institute for Safe Medication Practices (ISMP). Available from: http://www.ismp.org/Tools/tallmanletter s.pdf. Accessed January 23, 2016.

[27] Gerret D, Gale AG, Darker IT, et al. The Use of Tall Man Lettering to Minimise Selection Errors of Medicine Names in Computer Prescribing and Dispensing Systems. Loughborough University Enterprises Ltd.; 2009. Available from: http://webarchive.nationalarchives.gov.uk/2013050 2102046/http://www. connectingforhealth.nhs.uk/sys 
temsandservices/eprescribing/refdocs/tallman.pdf. Accessed January 23, 2016.

[28] ISMP's List of Error-Prone Abbreviations, Symbols and Dose Designations. Available from: https://www.ismp.org/tools/error proneabbreviations .pdf. Accessed January 18, 2016.

[29] Six drug errors you don't want to make. Available from: http://www . ausmed.com.au/blog/entry/high-risk-m edications-6-drug-errors-you-dont-want-to-make. Accessed January 18, 2016.

[30] Rollins CJ. Drug-nutrient interactions. In: Mueller CM, ed in chief. The A.S.P.E.N. Adult Nutrition Support Care Curriculum. 2nd ed. Silver Spring, MD: American Society for Parenteral and Enteral Nutrition; 2012: 298-307.

[31] Do Not Crush List. Institute for Safe Medication Practices (ISMP). Available from: http://www.ismp.org/Tools/DoNotCrush.pd f. Accessed January 23, 2016.

[32] Baxter K. ed. Stockley's Drug Interactions. 9th ed. London, UK: Pharmaceutical Press; 2010: 1-11.

[33] Genser D. Food and drug interaction: consequences for the nutrition/health status. Ann Nutr Metab. 2008; 52(suppl 1): 29-32.

[34] Schmidt L, Dalhoff K. Food-drug interactions. Drugs. 2002; 62(10): 1481-1501. http://dx.doi.org/10.2165/00003495-2002621 00-00005

[35] Food and Drug Administration. Avoid food-drug interactions: a guide from the National Consumers League and the U.S. Food and Drug Administration. Available from: http://www.fda.gov/downloads/Drugs/ResourcesForYo
u/Consumers/BuyingUsingMedicineSafely/EnsuringSafe UseofMedicine/GeneralUseofMedicine/UCM229033.pdf. Accessed January 23, 2016.

[36] Anderson KS, Bjorklund P. Demystifying federal nursing home regulations to improve the effectiveness of psychopharmacological care. Perspect Psychiatr Care. 2010 Apr; 46(2): 152-62.

[37] Gurwitz JH, Field TS, Avorn J, et al. Incidence and preventability of adverse drug events in nursing homes. Am J Med. 2000; 109: 87-94. http://dx.doi.org/10.1016/S0002-9343(00)00451-4

[38] Gurwitz JH, Field TS, Judge J, et al. Incidence of adverse drug events in two large academic long-term care facilities. Am J Med. 2005; 118(3): 251-58. PMid:15745723. http://dx.doi.org/10.1016 /j.amjmed.2004.09.018

[39] The Long Term Care Survey. October 2010 edition. Washington, DC: American Health Care Association; 2010: p 441.

[40] A systems approach to quality improvement in long-term care: safe medication practices workbook. MassPro Website. Available from: http://www.macoalition.org/Initiatives/do cs/safe_medication_practices_wkbk-2008.pdf. Accessed November 3, 2015.

[41] Handler, SM. Epidemiology of medication-related adverse events in nursing homes. Am J Geriatric Pharmacother. 2006; 4: 264 722. PMid:17062328. http://dx.doi.org/10.1016/j.amjop harm. 2006.09.011

[42] Institute of Medicine. Preventing Medication Errors: Quality Chasm Series. Chapter 2: Overview of the Drug Development, Regulation, Distribution and Use System. Washington, DC: The National Academies Press; 2007: 68. 